\title{
ARTICLE OPEN Exploring a possible connection between U.S. tornado activity and Arctic sea ice
}

\author{
Robert J. Trapp (D) and Kimberly A. Hoogewind ${ }^{2}$
}

The significant losses in Arctic sea ice over the past few decades appear to have been accompanied by changes in global-scale and regional-scale atmospheric circulation. Such circulation changes have in turn been used to support arguments that low Arctic seaice extent (SIE) has helped to promote extreme weather events within the mid-latitudes. The contemporaneous variability in U.S. tornado incidence over the past decade provides motivation to explore whether the essence of these arguments also applies to tornadoes. Here, robust statistical correlations are found between tornado activity and SIE during boreal summer, specifically in July. The statistical relationship is supported by the presence of anomalous regional circulation and storm track that are unfavorable (favorable) for tornado-bearing thunderstorm formation when SIE is low (high).

npj Climate and Atmospheric Science (2018)1:14; doi:10.1038/s41612-018-0025-9

\section{INTRODUCTION}

The significant losses in Arctic sea ice over the past few decades ${ }^{1}$ have been accompanied by lower-tropospheric temperature changes $^{2}$ that appear to have contributed to changes in globalscale and regional-scale atmospheric circulation. Such circulation changes-particularly the geographical shifts, enhanced undulations, blocking patterns, and speed reductions in the jet stream ${ }^{3-}$ ${ }^{7}$-have been used to support arguments that low Arctic sea ice helps to promote extreme weather events within the midlatitudes. ${ }^{8-10}$

We duly acknowledge the many criticisms of these arguments, which as recently summarized ${ }^{11}$ include the possibility that the variance (and trends) in weather extremes and their atmospheric forcings are masked by or convolved with high-frequency variability, subseasonal-to-seasonal (S2S) variability, multidecadal oscillations, and realizations of anthropogenically enhanced greenhouse gas (GHG) concentrations. ${ }^{10,12}$ Nonetheless, evidence of cryosphere-associated atmospheric circulation changes during boreal summer ${ }^{4-6}$ is particularly compelling here, because we and others are motivated by the possibility of exploiting long-memory processes for S2S predictions of tornado (and hail) activity ${ }^{13-16}$ during the boreal warm season.

For reference, the spatio-temporal distribution (i.e., climatology) of U.S. tornadoes is determined by geophysical features like the Rocky Mountains, Central Mexican Plateau, and the Gulf of Mexico, as well as by the seasonal variations in solar forcing and associated mean weather patterns. ${ }^{17}$ Our specific interest is in how the mean tornado occurrence would be modulated by anomalous anticyclonic circulation over central North America, which is one of the apparent cryosphere-associated atmospheric modifications during June-July-August (JJA). ${ }^{4}$ Consider that such anomalous circulation would cause a northward shift in the synoptic-scale forcing and 3D temperature, humidity, and wind distributions that favor intense-thunderstorm formation. ${ }^{17}$ Tornadogenesis within these storms requires precise spatial alignments of favorably distributed temperature, humidity, and wind, and thus any findings of decreases in zonal wind and wind shear ${ }^{5}$ would alone suggest a reduced likelihood for tornado formation.

This brief physical argument aside, our exploration is also motivated by the U.S. tornado incidence over the past decade, which except for a few years has been abnormally low, as has the Arctic sea ice. The purpose of this paper is to present initial evidence in support of the basic hypothesis is that low Arctic sea ice extent (SIE) contributes to a reduction in U.S. tornado activity as quantified by EF1+ tornado days (TOR).

\section{RESULTS}

Figure 1a shows that the linear correlations between detrended TOR and detrended pan-Arctic SIE are maximized during boreal summer, with a Pearson (Spearman rank) correlation coefficient $R_{\mathrm{p}}=+0.54\left(R_{\mathrm{s}}=+0.55\right)$ and $p=0.004$ in July. For reference, a linear regression using the raw time series yields $R_{\mathrm{p}}=+0.70, \mathrm{R}_{\mathrm{s}}=$ $+0.71, p=0.000$ in July (Fig. 1b); if we allow the time series to extend over a longer period (1980-2015), regression analyses using the raw and detrended data, respectively, yield $R_{\mathrm{p}}=+0.77$, $R_{\mathrm{s}}=+0.75, p=0.000$, and $R_{\mathrm{p}}=+0.48, R_{\mathrm{s}}=+0.48, p=0.003$ in July (Supplement Fig. S1). Although not the focus of this study, we additionally find that the F/EF1+ tornado reports over this longer time series correlate strongly with SIE in July $\left(R_{\mathrm{p}}=+0.57, R_{\mathrm{s}}=\right.$ $+0.55, p=0.000$ using raw data, and $R_{\mathrm{p}}=+0.45, R_{\mathrm{s}}=+0.40, p=$ 0.006 using detrended data; Supplement Fig. S2). All of the July correlations would be statistically significant at the $5 \%$ level even with application of a Bonferroni correction for multiple comparisons (12 months). ${ }^{18}$ This, incidentally, is not the case with correlations between TOR and Arctic Oscillation index, which are relatively low in July $\left(R_{\mathrm{p}}=-0.14, p=0.492\right)$ and in all other months.

These are contemporaneous correlations, but it would seem reasonable to also expect a lagged effect of Arctic sea ice on

\footnotetext{
${ }^{1}$ Department of Atmospheric Sciences, University of Illinois at Urbana, Champaign, USA and ${ }^{2}$ Department of Earth, Atmospheric, and Planetary Sciences, Purdue University, West Lafayette, USA

Correspondence: Robert J. Trapp (jtrapp@illinois.edu)
}

Received: 24 February 2018 Revised: 7 April 2018 Accepted: 18 April 2018 

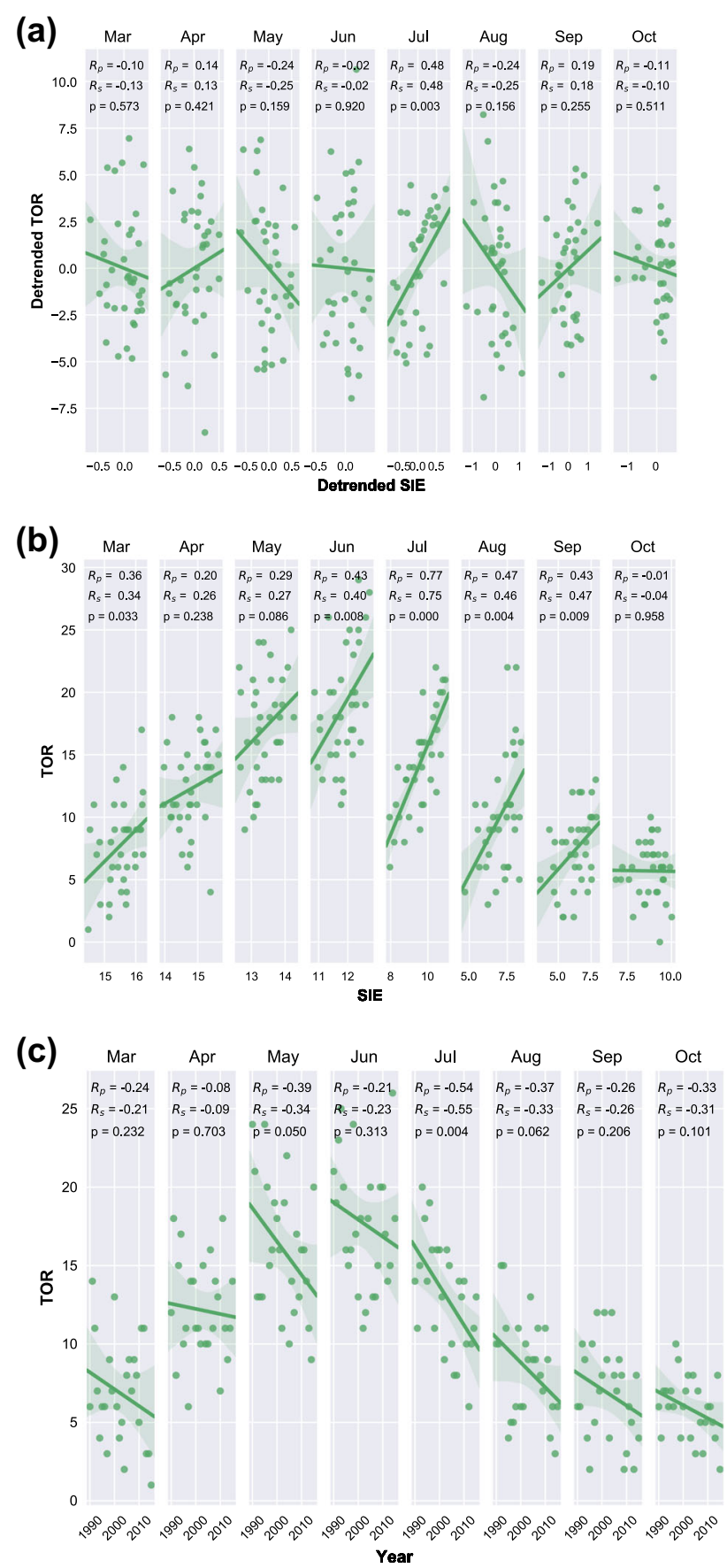

Fig. 1 Scatterplots of a detrended monthly mean sea-ice extent (SIE) versus detrended monthly E/EF1+ tornado days (TOR), b raw monthly mean SIE versus raw monthly TOR, and c time series of monthly TOR, all over the period 1990-2015. Solid lines show linear fit. Pearson correlation coefficient $\left(R_{\mathrm{p}}\right)$, Spearman rank correlation coefficient $\left(R_{s}\right)$, and $p$-value for each month are indicated near the top of each plot. Shading shows $95 \%$ confidence intervals from 10,000 bootstrapped resamples

tornado activity. Thus, we computed the linear regressions between detrended pan-Arctic SIE and the detrended TOR lagged by one and two months. Most of the lagged correlations are relatively low and statistically insignificant (Table 1), with notable exception of the regressions with July SIE. For example, Table 1 indicates that the 2-month lag of TOR from July SIE (i.e., July SIE and September TOR) results in $R_{\mathrm{p}}=+0.51$ (and $p=0.007$ ).
The 1-month lag of TOR from July SIE (i.e., July SIE and August TOR) results in $R_{\mathrm{p}}=+0.30$ (and $p=0.132$ ), which is higher than that between August SIE and August TOR, but still not statistically significant. The conclusion from this analysis is that July SIE is a key contributor to the statistical correlations with TOR.

Our hypothesis posed in the 'Introduction' regards pan-Arctic $\mathrm{SIE}$, but recent studies have identified specific Arctic sub-regions that promote geographically varying effects, e.g., ref. ${ }^{19}$ For example, anomalies in sea ice over the Barents-Kara Seas have been linked to anomalous large-scale circulation in the Northern Hemisphere during boreal winter specifically ${ }^{20,21}$ as well as during other parts of the year. Thus, we investigated the seven regions with non-zero SIE during this month (Table 2; see Supplement Fig. S3), with focus on July only, based on Fig. 1 and Table 1. In Table 2 we see that detrended TOR (with 0-month lag) has a statistically significant correlation only with detrended Barents-Kara Seas SIE $\left(R_{\mathrm{p}}=+0.46, p=0.018\right)$, which parallels well the pan-Arctic SIE correlation with TOR.

We note that these July SIE-TOR correlations are of comparable magnitude to correlations between tornadoes (and hail) and phases of El Niño/Southern Oscillation (ENSO) ${ }^{22,23}$ as well as ENSO phase transitions ${ }^{24}$ during boreal winter and spring, and to the global wind oscillation ${ }^{25}$ and Gulf of Mexico sea-surface temperatures $^{26,27}$ during boreal spring; certain phases of the Madden-Julian Oscillation (MJO) have additionally been used to explain variability in tornado and hail activity. ${ }^{28-30}$ During mid-tolate boreal summer, the influence of these drivers is reduced especially over the U.S. Great Plains, which is the climatologically favored region of tornado occurrence during this time. ${ }^{31}$ This perhaps explains why the high-latitude effects of Arctic SIE could possibly emerge in the July correlations relative to those in boreal spring and early summer.

Prima facie, tornadoes in July might seem unimportant when compared to those during boreal spring. Certainly, strong (F/EF3 +) TOR are relatively infrequent during this month (Fig. 2a), as also are tornado outbreaks and tornado fatalities. ${ }^{32}$ The frequency of F/ EF1+ TOR is, however, still quite high in July (Fig. 2b). July also contributes $12.7 \%$ of the annual F/EF1+ TOR, which is less than that of May (15.6\%) or June (16.9\%), but greater than that of April (11.4\%). In other words, the month of July is in fact a significant contributor to the annual tornado occurrence, especially given that low-end (F/EF0-1) tornadoes comprise the majority of the U.S. tornado population. ${ }^{33}$ Figure 2 also demonstrates a shift in the peak probability of tornado-day occurrence. This shift has been shown by others, ${ }^{34}$ but is worth mentioning here because it is associated with a non-uniform decline in tornado-day probabilities especially during May-July: the daily mean (F/EF1+) July probability of 0.45 over $1990-1999$ has decreased to 0.33 over 2006-2015, with this latter period corresponding to one of particularly rapid declines in SIE.

The negative trend in SIE extends over the entire period of 1990-2015, as does the trend in TOR, especially in late boreal spring through early boreal autumn (Fig. 1C). A negative trend in TOR over an even longer time series has been revealed by Brooks et al., ${ }^{35}$ albeit without reference to this seasonality or to a causality; a longer-term negative trend during JJA specifically has also recently been identified. ${ }^{36}$ The results presented in Fig. 1 demonstrate that the reduction in July activity is a primary contributor to the disaggregated trend shown by Brooks et al. ${ }^{35}$ (and to the JJA trend; ${ }^{36}$ ) as we discuss next, the causality is intimately related to the changes in the atmospheric circulation apparently associated with Arctic sea ice change.

Indeed, a physical argument that supports the statistical correlations between SIE and TOR can be based on aforementioned baroclinic linkages between Arctic sea ice and atmospheric circulation: In agreement with previous studies using other datasets, ${ }^{4,6}$ we find anomalously high (low) 500-hPa geopotential height, and anomalously anticyclonic (cyclonic) 500-hPa winds, in 
Table 1. Summary of linear regressions $\left(R_{\mathrm{p}} / p\right.$-value) between detrended TOR and detrended pan-Arctic SIE, for 0 -month, 1-month, and 2-month lags of TOR from SIE

\begin{tabular}{llllllll}
\hline & Mar TOR & Apr TOR & May TOR & Jun TOR & Jul TOR & Aug TOR & Sep TOR \\
\hline Jan SIE & $-0.11 / 0.587$ & & & & & \\
Feb SIE & $-0.19 / 0.362$ & $0.27 / 0.185$ & & & & \\
Mar SIE & $-0.10 / 0.573$ & $-0.11 / 0.593$ & $0.06 / 0.755$ & & & \\
Apr SIE & & $0.14 / 0.421$ & $0.22 / 0.280$ & $-0.05 / 0.792$ & & \\
May SIE & & & $-0.24 / 0.159$ & $0.26 / 0.208$ & $0.25 / 0.228$ & & \\
Jun SIE & & & $-0.02 / 0.920$ & $0.06 / 0.757$ & $0.19 / 0.350$ & $0.51 / 0.007$ \\
Jul SIE & & & & $0.48 / 0.003$ & $0.30 / 0.132$ & $0.26 / 0.197$ \\
Aug SIE & & & & & $-0.24 / 0.156$ & $0.19 / 0.364$ \\
Sep SIE & & & & & $0.19 / 0.255$ \\
Oct SIE & & & & & $0.38 / 0.057$ \\
\hline
\end{tabular}

Table 2. Summary of linear regressions between detrended July TOR and detrended July SIE averaged over seven regions (see Supplement Fig. S3) within the Arctic

\begin{tabular}{lll}
\hline Region & July $R_{\mathrm{p}}$ & July $p$ \\
\hline Baffin Bay & 0.39 & 0.051 \\
Barents-Kara Seas & 0.46 & 0.018 \\
Beaufort Sea & 0.03 & 0.869 \\
Chukchi Sea & -0.19 & 0.863 \\
East Siberia Sea & 0.32 & 0.117 \\
Greenland Sea & 0.05 & 0.844 \\
Hudson Bay & 0.33 & 0.100 \\
\hline
\end{tabular}

central North America, during July, for the five years with lowest (highest) detrended SIE over 1990-2015 (Fig. 3a, b). For comparison, the 500-hPa geopotential height and wind anomalies comprised of data from the five Julys with lowest (highest) detrended TOR over 1990-2015 are presented in Fig. 3c, d. Although lacking field significance, the respective difference fields in Fig. $3 e, f$ at least reveal the clear similarity in anomalous geopotential height for the high/low SIE and TOR years. This claim is supported by linear regressions between $500-\mathrm{hPa}$ geopotential height and inverted SIE (Fig. $3 \mathrm{~g}$ ) and inverted TOR (Fig. 3h): Both regression analyses exhibit positive correlations that are statistically significant over central North America in July (Fig. 3g, h); the regression slope patterns (not shown) mirror the correlationcoefficient patterns. Thus, our physical argument does not appear to depend on analysis approach. It is noteworthy that analyses using data from the months of May and June exhibit a clear lack of spatial similarity between the correlations resulting from SIEgeopotential height regressions and those from TOR-geopotential height regressions (Supplement Fig. S4). The month of July is unique in this regard.

The implied tendency during years of low SIE and TOR is of persistent midtropospheric ridging during July, as confirmed by analyses of daily $500-\mathrm{hPa}$ geopotential height (Supplement Fig. S5). When averaged over a month, this is realized as a northward extension of the July-mean western-U.S. ridge in $500-\mathrm{hPa}$ geopotential height, and a corresponding northward shift of the jet stream from its mean July position along the U.S.-Canada border. This shift can also expressed as a change in the July storm track, as confirmed in Fig. 4a, b by analyses of the maximum Eady growth rate $(\mathrm{EGR})^{37,38}$ at $600 \mathrm{hPa}$ :

$\sigma=-0.31 \frac{f}{N} g\left(\frac{p}{R T}\right)\left|\frac{\partial \vec{V}}{\partial p}\right|$,

where $f$ is the Coriolis parameter, $N$ is the Brunt-Väisälä frequency, $p$ is pressure, $R$ is the dry gas constant $\left(287 \mathrm{~J} \mathrm{~kg}^{-1} \mathrm{~K}^{-1}\right)$, and $\partial \vec{V} / \partial p$ is the vertical wind shear, evaluated here over the $700-500 \mathrm{hPa}$ layer, as was $N$. Of most relevance in Fig. $4 \mathrm{a}, \mathrm{b}$ is the reduction, during years of low SIE and TOR, in the frequency of tornadofavorable synoptic-scale disturbances especially over the central Great Plains (see Fig. 3a, c): this region encompasses the climatological maximum in tornado probability for July, and the premise is that significant changes in tornado occurrence are most readily brought about by modifications of the meteorological forcing within the climatological maximum.

A primary contributor to EGR is vertical wind shear, but vertical wind shear by itself is also a key ingredient for tornado development within deep convective storms. Figure 4c, d shows that the bulk wind shear over the $0-6 \mathrm{~km}$ layer (S06) is reduced (enhanced) over a broad region of the central U.S. during low (high) SIE and TOR years in July. This follows directly from existence of a central North American circulation anomaly and attendant modification of zonal wind (Fig. 3). Less extensive is a modification of convective available potential energy (CAPE) (Fig. $4 e, f)$, another key ingredient for tornadic-storm development. CAPE depends in part on the temperature lapse rate, which can be dynamically linked back to atmospheric circulation; local CAPE enhancements also arise through in situ evapotranspiration during summer, ${ }^{39,40}$ and would be less dependent on atmospheric circulation. Nevertheless, as noted above, a reduction in either of these key ingredients can inhibit tornado formation, and the S06 reduction appears to sufficiently explain the observed lack of July tornadic-storm occurrence over the climatological maximum within the central Great Plains. As an aside, we note that by this same argument, it could be possible that the S06 enhancement in Canada during low SIE years has led to enhanced July tornado activity during these years; however, as reperesented by available data, the occurence of Canadian tornadoes appears to be too sparse in time and space to provide robust statistics and address this argument.

It is reasonable to ask whether the infrequency of July tornadoes is additionally due to an overall suppression of all deep convective storms and their associated precipitation during low TOR years. This question is further motivated by findings of enhanced northern European summer precipitation by diminished Arctic sea ice, ${ }^{41}$ and by future-climate projections of reduced August rainfall in the central U.S., with a hypothesized link to 
(a)

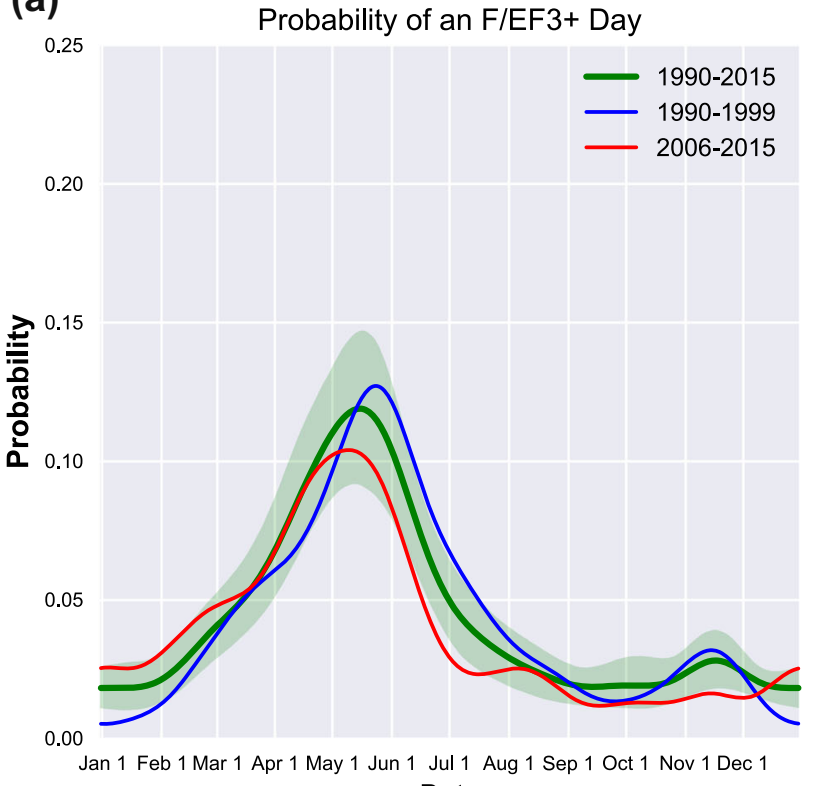

Date

(b)
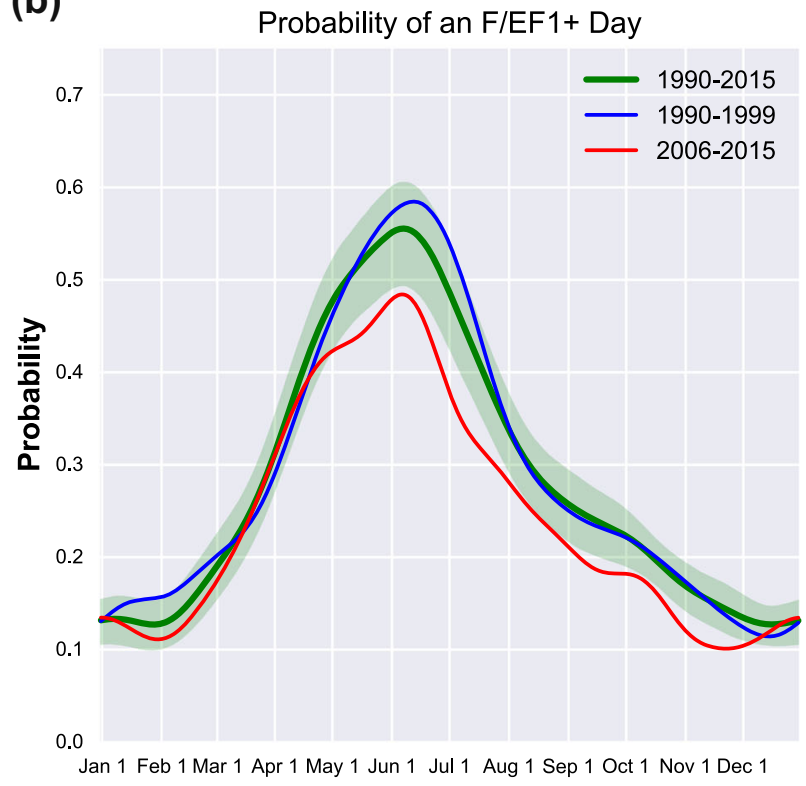

Date

Fig. 2 Probability of a tornado day within the U.S. as a function of calendar day, for tornadoes rated a F/EF3 and greater, and b F/EF1 and greater. The green curve represents a 26-y mean, with the lighter-green shading indicating the daily $95 \%$ confidence intervals determined from 10,000 bootstrapped resamples. The blue (red) curve shows the 10-y mean from 1990-1999 (2006-2015). A 15-day Gaussian filter was applied to the raw probabilities over each period. Note that the scales of the $y$-axis in (a) and (b) are different

Arctic Amplification. ${ }^{42}$ Here we consider July rainfall from the NOAA Climate Prediction Center unified gauge-based analysis of U.S. daily precipitation. ${ }^{43}$ We find reduced rainfall during low TOR and SIE years, in the form of negative anomalies in mean daily July precipitation over a large portion of the central U.S., including much of the central Great Plains and Midwest (Fig. 4g, h). The extension of the negative precipitation anomaly into the Midwest, beyond the region of anomalously low CAPE, is particularly compelling: Because deep convective (and at times tornadic) storms within the central Great Plains often grow upscale into mesoscale convective systems (MCSs), a suppression of these initial storms implies a subsequent lack of the eastwardpropagating MCSs that generate precipitation within and downstream of the Great Plains. ${ }^{44}$ This behavior is consistent with the anomalous storm track and associated anomalous forcings during low TOR and SIE years.

\section{DISCUSSION}

The preceding observation-based analyses demonstrate that the U.S. tornado activity in July is anomalously low (high) when panArctic sea ice is low (high) in July. The analyses also demonstrate that the atmospheric conditions during years of low (high) panArctic sea ice in July are generally unsupportive (supportive) of July tornado activity, and perhaps also of convective precipitation, particularly within the Great Plains region of the U.S. Such unsupportive conditions can be dynamically linked to anomalous circulation and storm track in central North America.

One limitation of our observational data is that they do not provide definitive proof that the anomalous regional circulation can necessarily be attributed to Arctic sea ice (perhaps specifically within the Barents-Kara Seas), nor do they rule out the possibility that tropical sea-surface temperatures also influenced the circulation during July 1990-2015 (although we do find that the statistical correlations between July TOR and July Oceanic Niño Index ${ }^{45}$ are small and insignificant during 1990-2015: $R_{\mathrm{p}}=-0.04$, $p=0.865)$. At an even more fundamental level, the data alone are insufficient to answer the question of whether the Arctic sea ice losses and associated lower-tropospheric temperature enhanced the atmospheric dynamics in July 1990-2015, or whether enhanced atmospheric dynamics drove larger ice losses, ${ }^{46}$ which then fed back to the dynamics. Future global modeling experiments will help resolve such questions.

Although the interannual variability in both TOR and SIE has been emphasized herein, one may ask how we can reconcile the observed negative trends in TOR (and SIE) with the projections of more frequent convective storminess under anthropogenic climate change (see ref. ${ }^{47}$ and references therein). In fact, recent high-resolution dynamical downscaling results ${ }^{47}$ for July alone do indicate a late-21st century reduction in the frequency of days with severe convective storms over the Great Plains region. Other regional climate model simulations ${ }^{48}$ also indicate rainfall reductions in July over this same region; such reductions are linked to a northward shift in the mean jet-stream position, which is effectively the argument made in the previous section. It is unclear, however, whether the trends revealed by these studies are specifically connected to Arctic sea ice loss, or, more generally to global radiative forcing owing to enhanced GHG concentrations. Future global modeling experiments will also help us address this question.

We close this section by revisiting the question of "Why July". Because of seasonal variations in mean position of the jet stream, the latitudinal zone of mean July S06 (e.g., $>15 \mathrm{~m} \mathrm{~s}^{-1}$ ) is narrower than, and positioned to the north of that of June (and also of May; see Supplement Fig. S6a,c,e). In contrast, the area of mean July CAPE (e.g., $>1000 \mathrm{~J} \mathrm{~kg}^{-1}$ ) is relatively broader than that of June (or May; see Supplement Fig. S6b,d,f). Hearkening back to our aforementioned comment about the need for precise spatial alignments of favorable environments, the implication of these monthly S06 and CAPE distributions is that tornadic-thunderstorm formation in July is, in the mean, relatively more sensitive to the existence of sufficient S06 than to CAPE. The further implication is that tornado formation in July is more sensitive to jet stream modulations; anecdotally, this is a common element of discussion by forecasters of severe convective weather.

The uniqueness of July SIE in this problem is less clear, but we believe that the annual cycle of SIE provides some clues. Consider that the average rate of SIE reduction during the month of July 

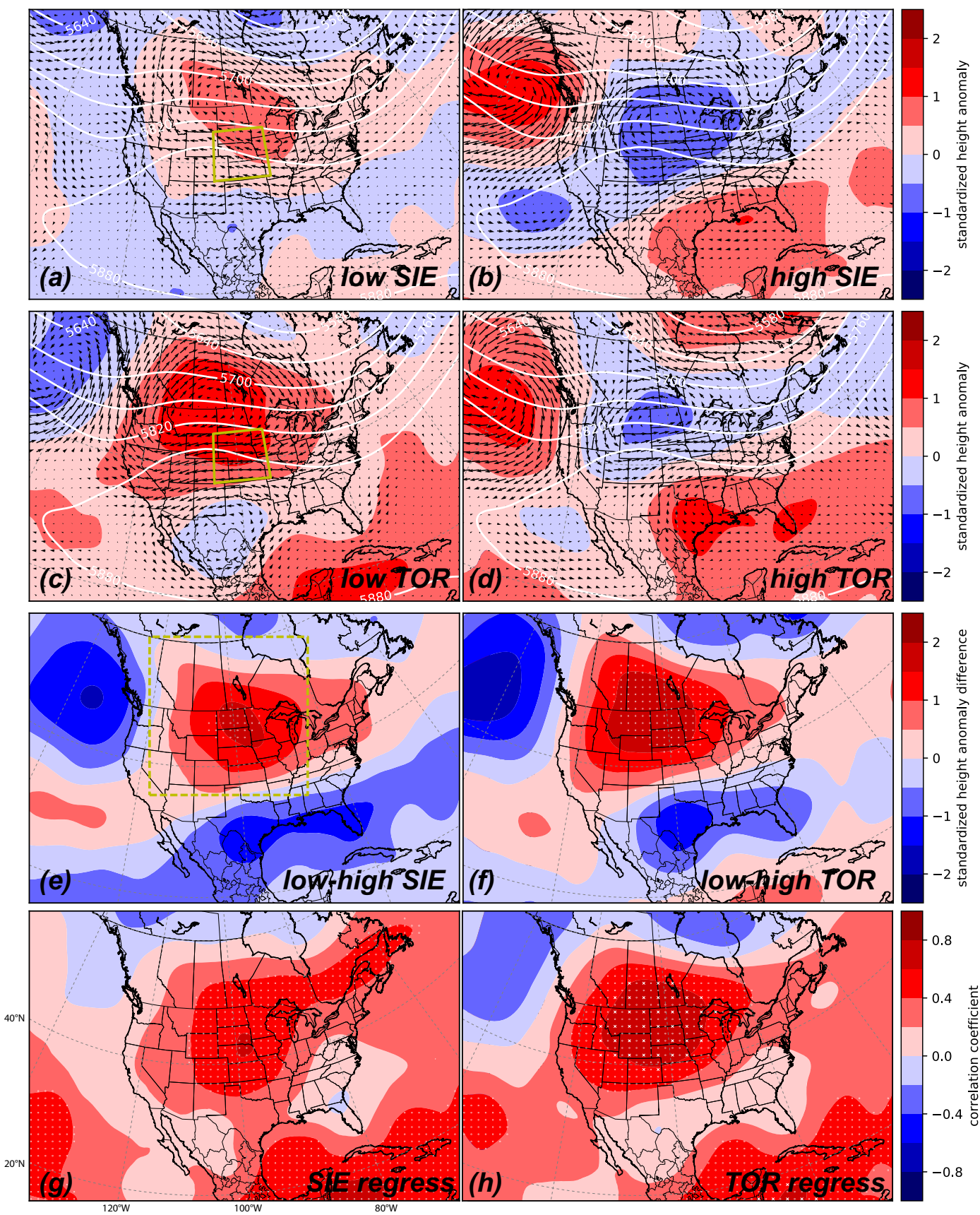

Fig. 3 Standardized mean anomalies in 500-hPa geopotential height (color fill) and wind (vectors) representing the five Julys with a lowest $(2007,1995,2011,1990,2012)$ and b highest $(2010,2004,1992,2015,1996)$ SIE over 1990-2015, and c lowest (1991, 2012, 2002, 2006, 2007) and d highest (2010, 2003, 2015, 1996, 1993) TOR over 1990-2015. The years are based on the linearly detrended time series. Differences between the respective SIE and TOR anomalies (low minus high) are shown in (e, f). Correlation coefficients from linear regressions between $500-\mathrm{hPa}$ geopotential height and inverted SIE and inverted TOR are shown in $(\mathbf{g}, \mathbf{h})$, respectively. Solid contours in (a-d) show July mean geopotential height. The solid yellow line in $(\mathbf{a}, \mathbf{c})$ indicates the location of the central Great Plains, and the dashed yellow line in $(\mathbf{e})$ shows the region over which local and global significance testing is conducted. The results of these tests (see text) are indicated in (e, $\mathbf{f})$, with white dots (white x's) showing locations where the local (global) hypotheses are rejected

(2.6 million $\mathrm{km}^{2} \mathrm{mon}^{-1}$ ) exceeds that of all other months (e.g., 1.73 million $\mathrm{km}^{2} \mathrm{mon}^{-1}$, for June, and 1.56 million $\mathrm{km}^{2} \mathrm{mon}^{-1}$ for August), as based on the 1981-2010 median values (Supplement Figure S5). During years of anomalously low July SIE, this rate is even larger.

We surmise that this relatively higher SIE transience during Julys of anomalously low SIE elicits a commensurate atmospheric response, perhaps in the form of enhanced Rossby-wave excitation. ${ }^{49}$ Whether, and exactly how, this may relate to tornado occurrence in the central U.S. awaits accumulation of additional data, and experimentation with coupled global models.

\section{DATA AND METHODS}

U.S. tornado activity is quantified using report data maintained by the NOAA Storm Prediction Center (SPC) (http://www.noaa.gov/ $w c m / \# d a t a)$. The limitations and biases of this dataset are well known. ${ }^{3,50}$ To minimize the impact of these biases, we have 

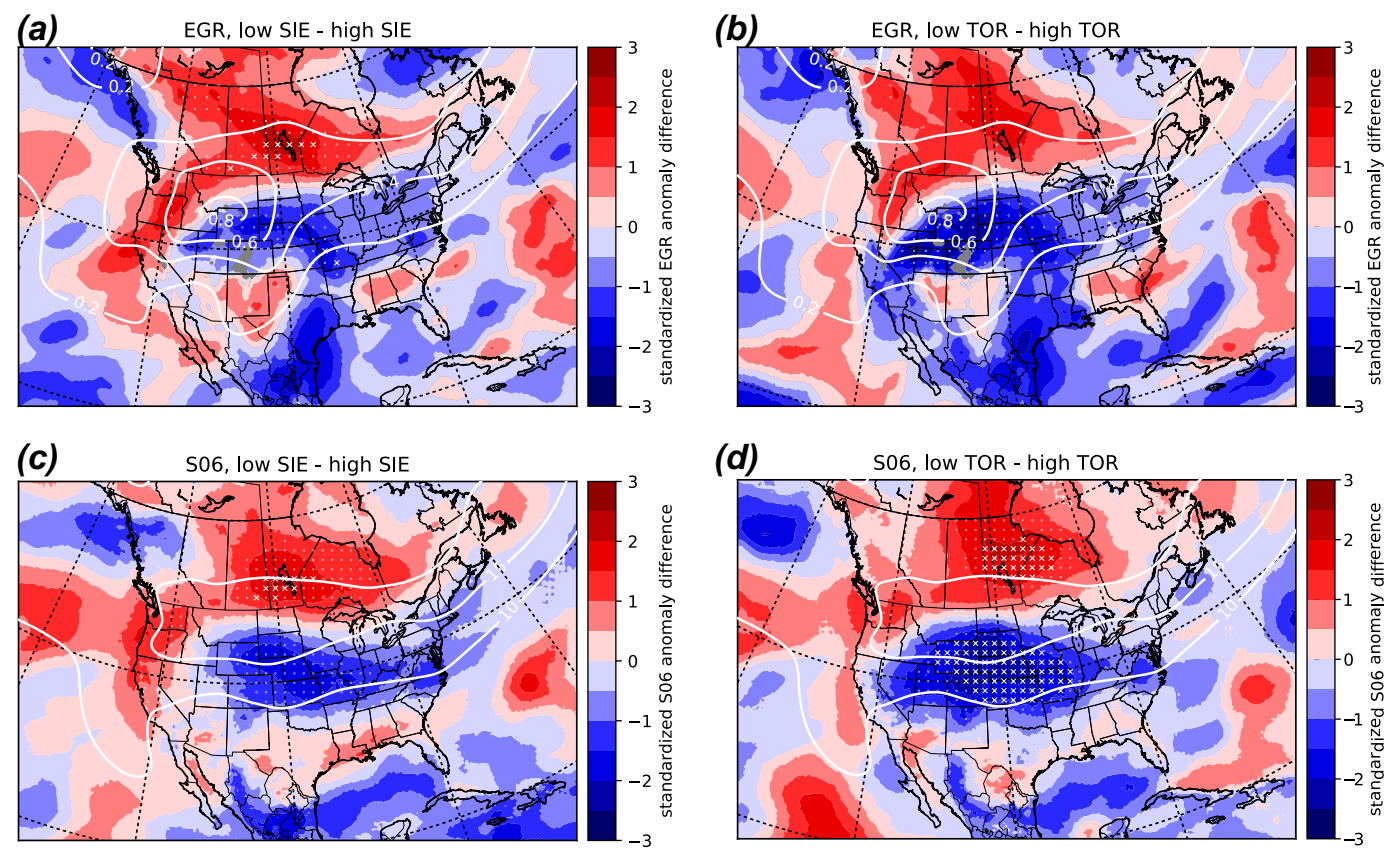

(d)
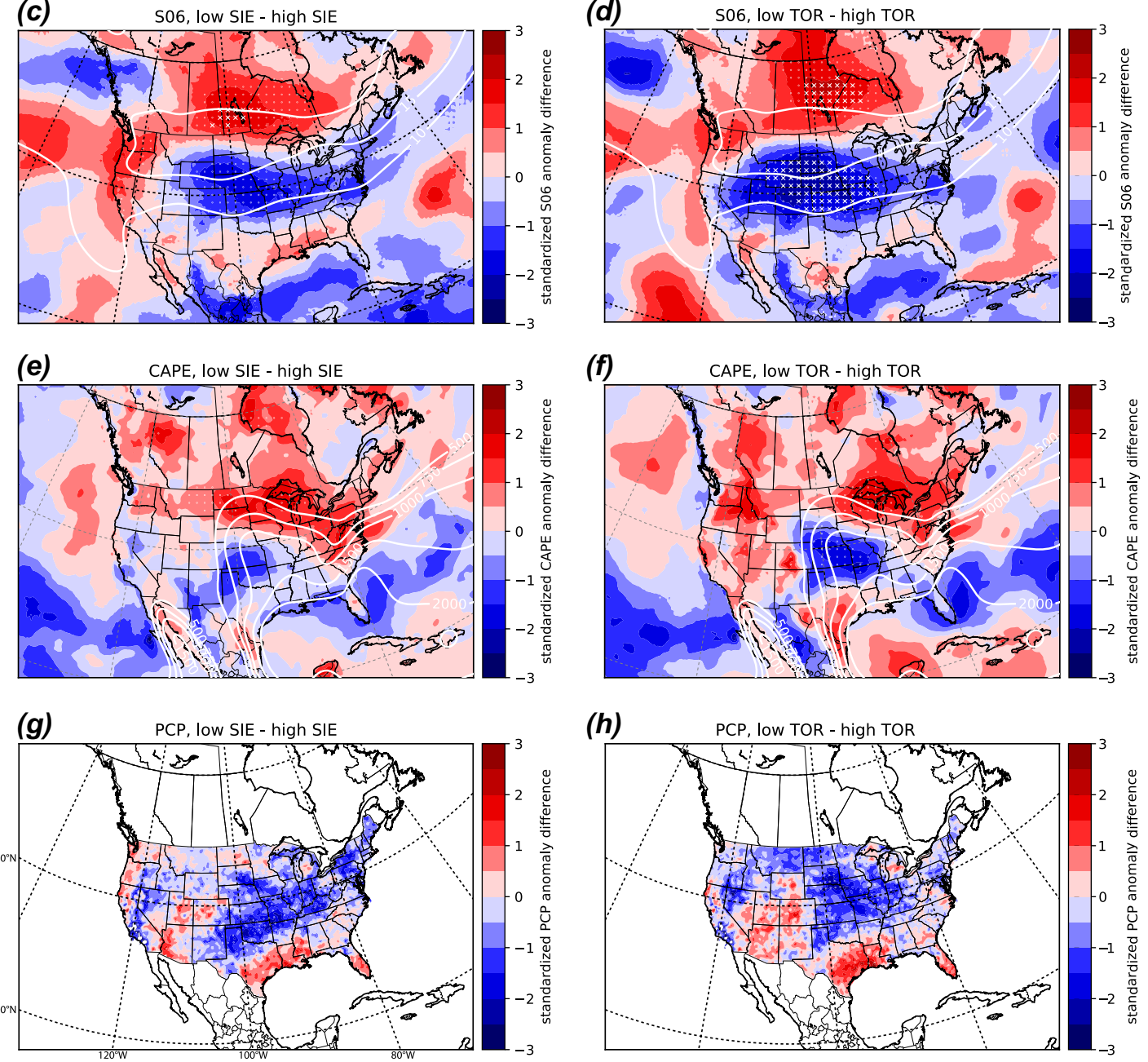

Fig. 4 Differences (low minus high) between the respective standardized mean anomalies for SIE and TOR in: $\mathbf{a}$, $\mathbf{b}$ Eady growth rate (EGR), c, $\mathbf{d}$ bulk vertical wind shear over the 0-6 km layer (S06), e, $\mathbf{f}$ convective available potential energy (CAPE), and $\mathbf{g}$, $\mathbf{h}$ daily precipitation rate (PCP) for July. White contours show July mean fields over 1981-2010. As in Fig. 3e, f, white dots (white x's) show locations where the local (global) hypotheses are rejected

limited our primary analysis to $1990-2015$, which is mostly during the era of the Next Generation Weather Radars (NEXRAD), ${ }^{51}$ and thus during a time when the report-data quality control has benefited from NEXRAD data; for completeness, we also present results using a longer time series (1980-2015), and are shown to be in agreement with the results from the shorter time series. We employ a tornado-day quantification, which is relatively insensitive to biases due to gross reporting errors. A TOR herein is a day (or period 1200 to 1159 UTC) on which at least one tornado rated 1 or greater on the Fujita/Enhanced Fujita (F/EF) scale occurred within the U.S., with leap-year days excluded. The use of a EF1+ threshold to define a tornado day has been well justified in previous studies. $^{35,52}$

We note here that we did consult a tornado database maintained by the Government of Canada (https://open.canada. $\mathrm{ca} /$ data/en/dataset/65658050-7a80-4da3-9a09-da137c203a34) for possible trends and spatial changes, but we found the tornado occurrence to be too sparse in time and space to provide robust statistics.

Arctic sea ice data are from the National Snow and Ice Data Center archive (http://nsidc.org). ${ }^{53}$ We use SIE, which is defined as the area with at least $15 \%$ sea-ice cover, and determined from Nimbus 7- SMMR/SSM/I and DMSP SSMI Passive Microwave data. 
Limitations and biases of these SIE data are discussed elsewhere. ${ }^{54}$ Pan-Arctic SIE as well as SIE determined within specific Arctic regions are considered. Trends are computed and then subsequently removed from monthly mean SIE as well as from monthly TOR data using a linear least-squares fit. The statistical significance of linear regressions between TOR and SIE is determined using a two-tailed $t$-test with a $5 \%$ significance level, with the null hypothesis that the regression slope is zero.

The North American Regional Reanalysis (NARR), ${ }^{55}$ obtained from the NOAA Earth System Research Laboratory (http://www. esrl.noaa.gov/psd/), is used to evaluate possible physical linkages between SIE and TOR. Composite standardized anomalies in relevant field variables are computed for the years with the five highest and five lowest SIE and TOR in July, based on the detrended data. The standardized anomaly is the anomaly from the 1981-2010 mean divided by the 1981-2010 standard deviation. Differences between the respective means from the low/high SIE and TOR composites are evaluated locally using a two-tailed $t$ test at a 5\% significance level, with the null hypothesis that the means are the same; field significance is evaluated over a subregion of the NARR domain (see Fig. $3 \mathrm{~g}$ ) using the false discovery rate (FDR) methodology ${ }^{56}$ with a $5 \%$ global significance level. Because of overlap in years contributing to the composites, we also evaluate possible physical linkages by linearly regressing SIE and TOR onto the NARR field variables. The statistical significance of these regressions is also determined using a twotailed $t$-test with a $5 \%$ significance level, with the null hypothesis that the regression slopes are zero.

\section{Data availability}

All data used in this study are freely available, and can be requested from the authors or obtained directly from the source: Tornado data: http://www.noaa.gov/wcm/\#data, Arctic sea ice data: http://nsidc.org, NARR and CPC precipitation data: http:// www.esrl.noaa.gov/psd/. These data were analyzed using the following Python libraries, all of which are available online: Matplotlib, Seaborn, Numpy, Scipy, netCDF4, CSV.

\section{ACKNOWLEDGEMENTS}

The authors would like to thank the National Snow and Ice Data Center for making available the sea-ice index data, the NOAA Storm Prediction Center for providing the tornado data, the NOAA Earth System Research Laboratory (ESRL) for providing the (NARR) reanalysis data as well as the NOAA Climate Prediction Center (CPC) U.S. Unified Precipitation data, and the NOAA CPC for generating this precipitation dataset. The authors would also like to acknowledge the helpful discussions with Drs. M. Tippett, H. Brooks, V. Gensini, J. Allen, Z. Wang, and S. Nesbitt, and the constructive comments made by the two anonymous reviewers. This research was funded through discretionary funds provided to the lead author by the Department of Atmospheric Sciences, University of Illinois at Urbana-Champaign.

\section{AUTHOR CONTRIBUTIONS}

R.J.T. designed the study and led the manuscript preparation. K.A.H. devised much of the analysis methodology and contributed to the manuscript preparation.

\section{ADDITIONAL INFORMATION}

Supplementary information accompanies the paper on the npj Climate and Atmospheric Science website (https://doi.org/10.1038/s41612-018-0025-9).

Competing interests: The authors declare no competing interests.

Publisher's note: Springer Nature remains neutral with regard to jurisdictional claims in published maps and institutional affiliations.

\section{REFERENCES}

1. Stroeve, J. C. et al. Trends in Arctic sea ice extent from CMIP5, CMIP3 and observations. Geophys. Res. Lett. 39, (2012).

2. Perlwitz, J., Hoerling, M. \& Dole, R. Arctic tropospheric warming: causes and linkages to lower latitudes. J. Clim. 28, 2154-2167 (2014).

3. Francis, J. A. \& Vavrus, S. J. Evidence for a wavier jet stream in response to rapid Arctic warming. Environ. Res. Lett. 10, 14005 (2015).

4. Tang, Q., Zhang, X. \& Francis, J. A. Extreme summer weather in northern midlatitudes linked to a vanishing cryosphere. Nat. Clim. Chang. 4, 45-50 (2014).

5. Coumou, D., Lehmann, J. \& Beckmann, J. The weakening summer circulation in the Northern Hemisphere mid-latitudes. Science 348, 324-327 (2015).

6. Petrie, R. E., Shaffrey, L. C. \& Sutton, R. T. Atmospheric response in summer linked to recent Arctic sea ice loss. Q. J. R. Meteorol. Soc. 141, 2070-2076 (2015).

7. Mann, M. E. et al. Influence of anthropogenic climate change on planetary wave resonance and extreme weather events. Sci. Rep. 7, 45242 (2017).

8. Francis, J. A., \& Vavrus, S. J. Evidence linking Arctic amplification to extreme weather in mid-latitudes. Geophys. Res. Lett. 39, (2012).

9. Overland, J. et al. The melting Arctic and midlatitude weather patterns: are they connected? J. Clim. 28, 7917-7932 (2015)

10. National Research Council. Linkages between Arctic warming and mid-latitude weather patterns: Summary of a workshop. (2014). https://doi.org/10.17226/18727

11. Francis, J. A. Why are Arctic linkages to extreme weather still up in the air? Bull. Am. Meteor. Soc. 98, 2551-2557 (2017).

12. Screen, J. A., Deser, C., Simmonds, I. \& Tomas, R. Atmospheric impacts of Arctic sea-ice loss, 1979-2009: separating forced change from atmospheric internal variability. Clim. Dyn. 43, 333-344 (2014).

13. Trapp, R. J. On the significance of multiple consecutive days of tornado activity. Mon. Wea. Rev. 142, 1452-1459 (2014).

14. Tippett, M. K., Sobel, A. H., Camargo, S. J. \& Allen, J. T. An Empirical relation between U.S. tornado activity and monthly environmental parameters. J. Clim. 27, 2983-2999 (2014).

15. Lepore, C., Tippett, M. K. \& Allen, J. T. ENSO-based probabilistic forecasts of March-May U.S. tornado and hail activity. Geophys. Res. Lett. 44, 9093-9101 (2017).

16. Gensini, V. A. \& Allen, J. T. U.S. hail frequency and the global wind oscillation. Geophys. Res. Lett. 45 (2018) https://doi.org/10.1002/2017GL076822

17. Trapp, R. J. Mesoscale-Convective Processes in the Atmosphere. (Cambridge University Press, New York, 2013).

18. Wilks, D. S. Statistical methods in the atmospheric sciences. (Academic Press, Oxford, 2005).

19. Screen, J. A. Simulated atmospheric response to regional and Pan-Arctic Sea ice loss. J. Clim. 30, 3945-3962 (2017).

20. Petoukhov, V., \& Semenov, V. A. A link between reduced Barents-Kara sea ice and cold winter extremes over northern continents. J. Geophys. Res. Atmos. 115, (2010).

21. Ruggieri, P., Kucharski, F., Buizza, R. \& Ambaum, M. H. P. The transient atmospheric response to a reduction of sea-ice cover in the Barents and Kara Seas. $Q$. J. R. Meteorol. Soc. 143, 1632-1640 (2017).

22. Allen, J. T., Tippett, M. K. \& Sobel, A. H. Influence of the El Nino/Southern Oscillation on tornado and hail frequency in the United States. Nat. Geosci. 8, 278-283 (2015).

23. Cook, A. R., Leslie, L. M., Parsons, D. B. \& Schaefer, J. T. The Impact of E Niño-Southern Oscillation (ENSO) on winter and early spring U.S. tornado outbreaks. J. Appl. Meteorol. Climatol. 56, 2455-2478 (2017).

24. Lee, S.-K., Atlas, R., Enfield, D., Wang, C. \& Liu, H. Is there an optimal ENSO pattern that enhances large-scale atmospheric processes conducive to tornado outbreaks in the United States? J. Clim. 26, 1626-1642 (2012)

25. Gensini, V. A. \& Marinaro, A. Tornado frequency in the United States related to global relative angular momentum. Mon. Wea. Rev. 144, 801-810 (2016).

26. Molina, M. J., Timmer, R. P. \& Allen, J. T. Importance of the Gulf of Mexico as a climate driver for U.S. severe thunderstorm activity. Geophys. Res. Lett. 43 (2016). https://doi.org/10.1002/2016GL071603

27. Jung, E. \& Kirtman, B. P. Can we predict seasonal changes in high impact weather in the United States? Environ. Res. Lett. 11, 74018 (2016).

28. Barrett, B. S. \& Gensini, V. A. Variability of central United States April-May tornado day likelihood by phase of the Madden-Julian Oscillation. Geophys. Res. Lett. 40, 2790-2795 (2013).

29. Thompson, D. B. \& Roundy, P. E. The relationship between the Madden-Julian oscillation and U.S. violent tornado outbreaks in the spring. Mon. Wea. Rev. 141 2087-2095 (2013).

30. Barrett, B. S. \& Henley, B. N. Intraseasonal variability of hail in the contiguous United States: relationship to the Madden-Julian oscillation. Mon. Wea. Rev. 143, 1086-1103 (2015).

31. Brooks, H. E., Doswell, C. A. \& Kay, M. P. Climatological estimates of local daily tornado probability for the United States. Wea. Forecast. 18, 626-640 (2003). 
32. Ashley, W. S. Spatial and temporal analysis of tornado fatalities in the United States: 1880-2005. Wea. Forecast. 22, 1214-1228 (2007).

33. Brooks, H., Doswell, C. A. \& Doswell, C. A. III Some aspects of the international climatology of tornadoes by damage classification. Atmos. Res. 56, 191-201 (2001).

34. Long, J. A. \& Stoy, P. C. Peak tornado activity is occurring earlier in the heart of 'Tornado Alley'. Geophys. Res. Lett. 41, 6259-6264 (2014).

35. Brooks, H. E., Carbin, G. W. \& Marsh, P. T. Increased variability of tornado occurrence in the United States. Sciience 346, 349-352 (2014).

36. Moore, T. W. Annual and seasonal tornado activity in the United States and the global wind oscillation. Clim. Dyn. (2017). https://doi.org/10.1007/s00382-0173877-5

37. Lindzen, R. S. \& Farrell, B. A simple approximate result for the maximum growth rate of baroclinic instabilities. J. Atmos. Sci. 37, 1648-1654 (1980).

38. Hoskins, B. J. \& Valdes, P. J. On the existence of storm-tracks. J. Atmos. Sci. 47, 1854-1864 (1990).

39. Raddatz, R. L. Summer rainfall recycling for an agricultural region of the Canadian prairies. Can. J. Soil Sci. 80, 367-373 (2000).

40. Clark, C. A. \& Arritt, P. W. Numerical simulations of the effect of soil moisture and vegetation cover on the development of deep convection. J. Appl. Meteorol. 34, 2029-2045 (1995).

41. Screen, J. A. Influence of Arctic sea ice on European summer precipitation. Environ. Res. Lett. 8, 44015 (2013).

42. Vavrus, S. J. et al. Changes in North American atmospheric circulation and extreme weather: influence of Arctic amplification and Northern hemisphere snow cover. J. Clim. 30, 4317-4333 (2017).

43. Chen, M., Xie, P. \& Co-authors. CPC unified gauge-based analysis of global daily precipiation. in Western Pacific Geophysics Meeting (2008).

44. Carbone, R. E., Tuttle, J. D., Ahijevych, D. A. \& Trier, S. B. Inferences of predictability associated with warm season precipitation episodes. J. Atmos. Sci. 59, 2033-2056 (2002).

45. NOAA/CPC. Oceanic Nino Index. NOAA/Climate Prediction Center. Subset used: 1990-2015, accessed October 2017 (2017). http://origin.cpc.ncep.noaa.gov/ products/analysis_monitoring/ensostuff/ONI_v5.php

46. Wernli, H. \& Papritz, L. Role of polar anticyclones and mid-latitude cyclones for Arctic summertime sea-ice melting. Nat. Geosci. 11, 108-113 (2018).

47. Hoogewind, K. A., Baldwin, M. E. \& Trapp, R. J. The impact of climate change on hazardous convective weather in the United States: insight from high-resolution dynamical downscaling. J. Clim. 30, 10081-10100 (2017).
48. Bukovsky, M. S., McCrary, R. R., Seth, A. \& Mearns, L. O. A mechanistically credible, poleward shift in warm-season precipitation projected for the U.S. Southern Great Plains? J. Clim. 30, 8275-8298 (2017).

49. Honda, M., Inoue, J., \& Yamane, S. Influence of low Arctic sea-ice minima on anomalously cold Eurasian winters. Geophys. Res. Lett. 36, (2009).

50. Trapp, R. J. \& Brooks, H. E. Regional characterization of tornado activity. J. Appl. Meteorol. Climatol. 52, 654-659 (2013).

51. Whiton, R. C., Smith, P. L., Bigler, S. G., Wilk, K. E. \& Harbuck, A. C. History of operational use of weather radar by U.S. weather services. Part I: The Pre-NEXRAD era. Wea. Forecast. 13, 219-243 (1998).

52. Tippett, M. K., Allen, J. T., Gensini, V. A. \& Brooks, H. E. Climate and hazardous convective weather. Curr. Clim. Chang. Rep. 1, 60-73 (2015).

53. Cavalieri, D. J., Parkinson, C. L., Gloersen, P. \& Zwally, H. J. Sea Ice Concentrations from Nimbus-7 SMMR and DMSP SSM/I-SSMIS Passive Microwave Data, Version 1. (1996). https://doi.org/10.5067/8GQ8LZQVLOVL

54. Overeem, I. et al. Sea ice loss enhances wave action at the Arctic coast. Geophys. Res. Lett. 38, L17503 (2011).

55. Mesinger, F. et al. North American regional reanalysis. Bull. Am. Meteor. Soc. 87, 343-360 (2006).

56. Wilks, D. S. 'The stippling shows statistically significant grid points': how research results are routinely overstated and overinterpreted, and what to do about It. Bull. Am. Meteor. Soc. 97, 2263-2273 (2016).

(c) Open Access This article is licensed under a Creative Commons By Attribution 4.0 International License, which permits use, sharing, adaptation, distribution and reproduction in any medium or format, as long as you give appropriate credit to the original author(s) and the source, provide a link to the Creative Commons license, and indicate if changes were made. The images or other third party material in this article are included in the article's Creative Commons license, unless indicated otherwise in a credit line to the material. If material is not included in the article's Creative Commons license and your intended use is not permitted by statutory regulation or exceeds the permitted use, you will need to obtain permission directly from the copyright holder. To view a copy of this license, visit http://creativecommons. org/licenses/by/4.0/.

(c) The Author(s) 2018 